\title{
Correction to: Categorizing the influences of two large seabird colonies on island freshwater ecosystems in the Northwest Atlantic Ocean
}

\author{
Matthew P. Duda $(\mathbb{D} \cdot$ Neal Michelutti $\mathbb{D} \cdot$ Xiaowa Wang $\cdot$ John P. Smol $\mathbb{C}$
}

Published online: 26 January 2021

(C) Springer Nature Switzerland AG 2021

Correction to: Hydrobiologia

https://doi.org/10.1007/s10750-020-04498-2

Due to an unfortunate mistake during the production process, the inset map in Fig. 1a is missing. The original article has been corrected and the correct display of Fig. 1 is also published here.

The original article can be found online at https:// doi.org/10.1007/s10750-020-04498-2.

M. P. Duda $(\varangle)$ · N. Michelutti · J. P. Smol Paleoecological Environmental Assessment and Research Lab (PEARL), Department of Biology, Queen's University, Kingston, ON K7L 3N6, Canada e-mail: 16mpd3@queensu.ca

X. Wang

Aquatic Ecosystem Protection Research Division, Environment and Climate Change Canada, Burlington, ON L7S 1A1, Canada 

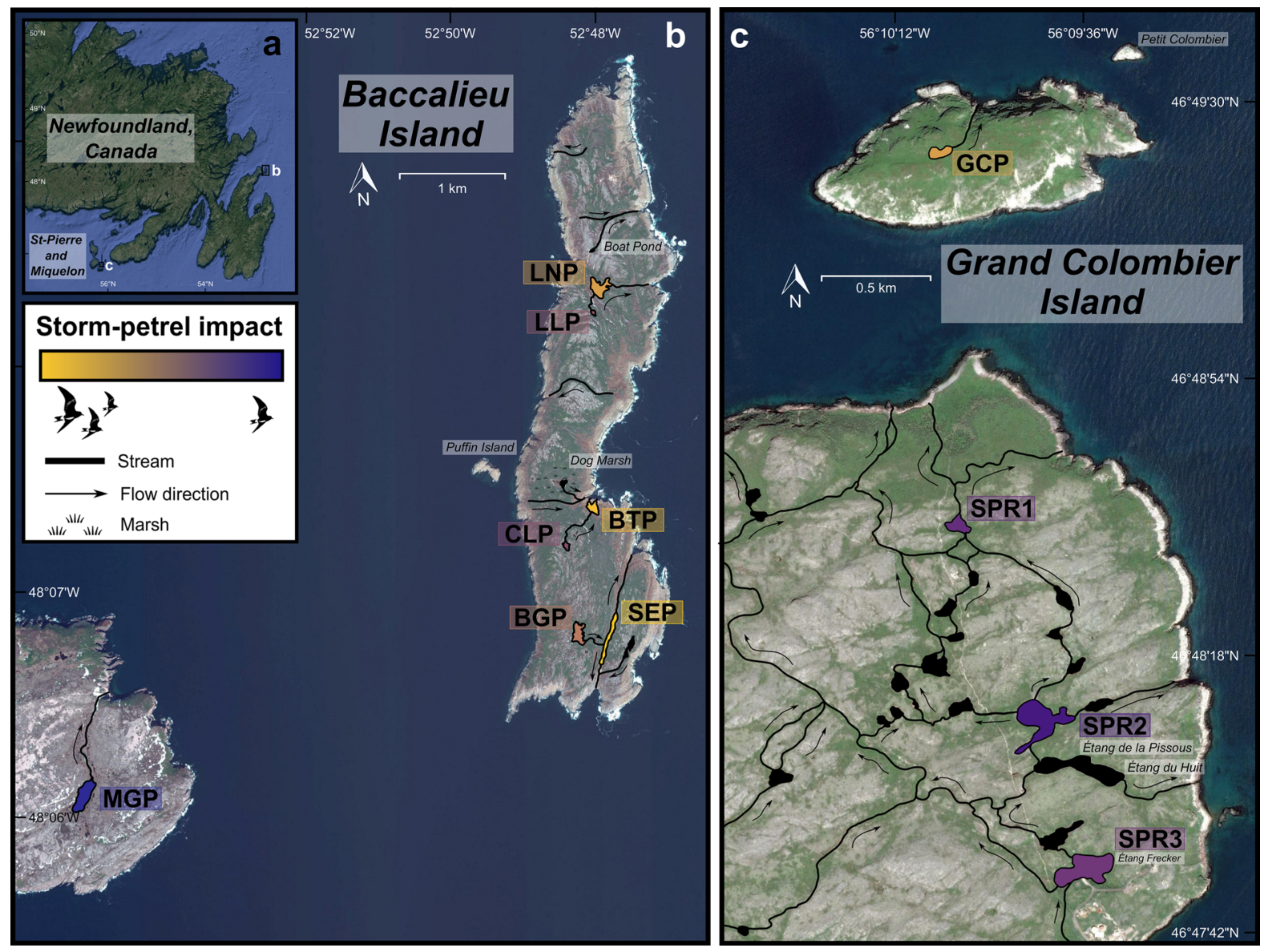

Fig. 1 Map of study ponds and inferred storm-petrel impacts. a Map of Eastern Newfoundland with the locations of b Baccalieu Island in Newfoundland and Labrador, Canada and $\mathbf{c}$ Grand Colombier Island, St. Pierre and Miquelon, France.
All studied ponds are presented in the colour of relative to impact as determined using a PCA (Fig. 5), and unstudied ponds are in black. Table 1 lists the study location names in full

Publisher's Note Springer Nature remains neutral with regard to jurisdictional claims in published maps and institutional affiliations. 